\title{
Estudo do comportamento resiliente de cinco solos finos da ilha de São Luís para fins de pavimentação
}

O avanço da mecânica dos pavimentos tornou possível analisar a deformabilidade de solos à aplicação de cargas cíclicas, e assim representar melhor a condição de campo. Pensando nisso este trabalho tem como objetivo investigar o comportamento resiliente de solos finos provenientes da região de São Luís, no estado do Maranhão, como alternativa para emprego em camadas de pavimento. Foram estudados sete solos, classificados segundo a Metodologia MCT como: um solo laterítico argiloso, três solos lateríticos arenosos e três solos não lateríticos siltosos. Após a caracterização geotécnica, foram moldados corpos de prova a energia proctor modificado para determinação do módulo de resiliência pelo ensaio de triaxial de cargas repetidas. Em seguida com o auxílio do programa STATISTICA 2.0 foram realizados tratamentos estatísticos para definir o melhor modelo de previsão de comportamento resiliente. Os resultados mostraram que os modelos que melhor se encaixaram foram o modelo estatístico proposto pela NCHRP (2014) e o modelo composto proposto por Pezo et al. (1992). Todas as amostras estudadas apresentaram valores de Módulo de Resiliência adequados para o emprego em camadas de pavimento. Dessa forma, esta pesquisa foi fundamental para contribuir o banco de dados de solos brasileiros com o comportamento mecânico de solos da região, assim, melhor a acurácia de projetos de pavimentação.

Palavras-chave: Módulo de resiliência; Solos finos; Análise mecanicista; Solos tropicais.

\section{Study of the resilient behavior of five fine soils on the island of São Luís for paving purposes}

\begin{abstract}
The advancement of pavement mechanics made it possible to analyze the deformability of soils when applying cyclic loads, and thus better represent the field condition. With this in mind, this work aims to investigate the resilient behavior of fine soils from São Luís region, state of Maranhão, as an alternative for use in pavement layers. We studied seven soils, classified according to the MCT Methodology as: one lateritic clayey soil, three lateritic sandyey soils and three nonlateritic siltyey soils. After geotechnical characterization, specimens were molded with modified proctor energy to determine the resilience module by the repeated load triaxial test. Then, with the aid of the STATISTICA 2.0 program, statistical treatments were carried out to define the best model for predicting resilient behavior The results showed that the models that best fit were the statistical model proposed by NCHRP (2014) and the composite model proposed by Pezo et al. (1992). All the studied samples presented Resilience Modulus values suitable for use in pavement layers. Thus, the research contributed to complete the database of the mechanical behavior of soils of the region and, then, better the accuracy of paving projects.
\end{abstract}

Keywords: Resilience module; Fine soils; Mechanistic analysis; Tropical soils.

Topic: Sustentabilidade nos Transportes

Reviewed anonymously in the process of blind peer.
Received: 02/08/2020

Approved: 19/09/2020
Gleyciane Almeida Serra (iD)

Instituto Militar de Engenharia, Brasil

http://lattes.cnpq.br/9865970493705695

http://orcid.org/0000-0002-9438-4089

gleyciakira@gmail.com

Antonio Carlos Rodrigues Guimarães (iD)

Instituto Militar de Engenharia, Brasil

http://lattes.cnpq.br/8890983301899546

http://orcid.org/0000-0001-9244-7034

guimaraes@ime.eb.br

Maria Esther Soares Marques (iD)

Instituto Militar de Engenharia, Brasil

http://lattes.cnpq.br/8911936841113704

http://orcid.org/0000-0001-8936-2777

esther@ime.eb.br
Carmen Dias Castro

Instituto Militar de Engenharia, Brasil

http://lattes.cnpq.br/7327516757339223

carmendc14@gmail.com
Referencing this:

SERRA, G. A.; GUIMARÃES, A. C. R.; MARQUES, M. E. S.; CASTRO, C. D.. Estudo do comportamento resiliente de cinco solos finos da ilha de São Luís para fins de pavimentação. Revista Ibero Americana de Ciências Ambientais, v.11, n.5, p.376-389, 2020. DOI: http://doi.org/10.6008/CBPC2179-6858.2020.005.0035 


\section{INTRODUÇÃO}

O pavimento forma um sistema de camadas com complexas relações de esforços mecânicos. Por muito tempo, o desempenho mecânico dos pavimentos tem sido avaliado em função do Índice de Suporte Califórnia (ISC), recomendado pelas normas vigentes brasileiras. Apesar de décadas de calibragem fundamentado em um banco de dados robusto, o ensaio não é capaz de prever com clareza os efeitos causados na estrutura (FRANCO, 2007). Entre as deficiências desse ensaio ressalta-se que, o ISC não representa o efeito real das cargas no pavimento, uma vez que não considera as tensões de confinamento e não leva em conta a aplicação dinâmica das cargas, causada pelos veículos em movimento (NGUYEN et al., 2016). Além disso, o fenômeno de resistência a penetração não é o principal fator que leva a perda de serventia do pavimento, em geral, a ruptura do pavimento é ocasionada da deformação excessiva das camadas ou fadiga devido a cargas cíclicas do revestimento.

Destaca-se, ainda, que o CBR apresenta resultados baseados na correlação de resistência com uma brita graduada padrão, uma vez que elaborado nos Estados Unidos para o material tipicamente utilizado nas camadas de pavimento do país. Entretanto, no Brasil, devido à abundância de solos tropicais, faz-se cada vez mais frequente o uso desse tipo de material em camadas do pavimento. Como consequência, os resultados de ISC para solos encontrados na literatura para solos, têm apresentado elevada variabilidade. Este fato pode estar relacionado as quebras dos grumos e concreções ao se compactar solos em laboratório, o que difere do comportamento dos materiais britados (MEDINA, 1989). Materiais granulares apresentam valores de CBR alto devido ao atrito dos Em contrapartida, os solos finos apresentam baixa deformabilidade elástica devido aos campos eletromagnéticos gerados pelas partículas (DNIT, 2006).

Nos manuais de dimensionamento de pavimentos da AASTHO (AASTHO, 1993) e da AUSTROADS (AUTROADS, 2012) é fortemente recomendado o Módulo de Resiliência para previsão de desempenho mecânico das camadas granulares. Métodos mecanicista-empíricos, embora ainda não normatizados no Brasil, tem se mostrado mais eficientes, fornecendo especificações mais precisas (YUAN et al., 2003). Diversos autores estudaram este ensaio para em solos brasileiros (PREUSSLER, 1978; SVENSON, 1980); MEDINA et al., 1980; Ll et al., 1994; MEDINA et al., 2006; GUIMARÃES et al., 2012) e fizeram a aplicação de um dimensionamento mecanístico-empírico (FRANCO, 2007; BASTOS, 2013; MEDINA et al., 2015; SANTOS, 2016; FERNANDES, 2016; FERNANDES et al., 2017).

Como alternativa para redução de custos de obras rodoviárias, especialmente para rodovias de baixo tráfego, a utilização de solos lateríticos finos em camadas de pavimento têm se mostrado promissora. Particularidades ligadas às suas composições, óxidos de ferro e de alumínio, revelam um desempenho mecânico superior aos solos saprolíticos. Contudo, os sistemas de classificações tradicionais, HRB (Highway Research Board) e USCS (Unifield Soil Classification System), não são apropriados para distinguir os solos tropicais brasileiros. Ignorando as peculiaridades do comportamento laterítico, evidenciadas por diversos autores, e incluídas da metodologia MCT (Miniatura, Compactado, Tropical) (NOGAMI et al., 1983; CARDOSO, 1988; RODRIGUES, 1997; SANTOS et al., 2019). 
Diante do cenário exposto, a pesquisa objetiva compreender o comportamento resiliente de solos finos da região de São Luís, no estado do Maranhão e analisar o enquadramento dos modelos de previsão de comportamento já consagrados. Dessa forma, contribuir com o método de dimensionamento mecanístico brasileiro, atualmente em elaboração, carente de um banco de dados de solos da região.

\section{REVISÃO TEÓRICA}

A mecânica dos pavimentos traz uma abordagem com base ensaios dinâmicos que permite analisar as deformações elásticas à plásticas frente a níveis de tensões. A relação entre as tensões aplicadas e a correspondente deformação recuperável consiste no módulo de resiliência, que para sua estimativa a principal ferramenta laboratorial aplicada é o ensaio triaxial cíclico, no qual obtém-se um controle maior das condições da amostra, além dos deslocamentos medidos bem como dos carregamentos aplicados. No entanto, as respostas obtidas do ensaio são predominantemente não lineares, sendo necessário utilizar relações empíricas entre os valores de módulo de resiliência e o estado de tensões (SPADA, 2003). Há vários modelos para representar o módulo de resiliência a partir de resultados de ensaios triaxiais. Alguns desses modelos se baseiam em uma análise de regressão entre os valores de Módulo de Resiliência (MR) e componentes de tensões.

A maioria dos materiais apresenta uma grande dependência em relação ao estado de tensões. Em razão disso, diversos modelos foram criados buscando modelar o MR em função das tensões aplicadas aos materiais (RIBEIRO, 2016). Viana (2007), cita em seu trabalho que o módulo de resiliência dos solos, representado por muitos modelos (descritos nos trabalhos de Hicks et al. (1971), Uzan (1985) e Witczak et al. (1988, citado por TUTUMLUER et al., 1998)) levam basicamente em consideração as tensões atuantes no solo. A Tabela 2 ilustra um resumo de algumas equações usadas para modelar o módulo resiliente avaliadas por pesquisadores no mundo todo.

Tabela 1: Propriedades físicas típicas de escória de aciaria.

\begin{tabular}{ll}
\hline Equações & Referências \\
\hline$M_{r}=k_{1} * \sigma_{3}^{k_{2}}(1)$ & Dunlap (1963) \\
$M_{r}=k_{1} * \sigma_{d}^{k_{2}}(2)$ & Moossazadeh et al. (1981) \\
$M_{r}=k_{1} * \theta^{k_{2}}(3)$ & Seed et al. (1967) \\
$M_{r}=k_{1} * \theta^{k_{2}} * \sigma_{d}^{k_{3}}(4)$ & Uzan (1985) \\
$M_{r}=k_{1} * \sigma_{3}^{k_{2}} * \sigma_{d}^{k_{3}}(5)$ & Pezo et al. (1992) \\
$M_{r}=k_{1} * \theta^{k_{2}} * \tau_{o c t}^{k_{3}}(6)$ & Witczak et al. (1988) \\
$M_{r}=k_{1} * \theta^{k_{2}} *\left(\tau_{o c t}^{k_{3}}+1\right)(7)$ & NCHRP 1-28A (2004) \\
\hline
\end{tabular}

*Tensão volumétrica ou invariante de tensão $\left(\theta^{k_{2}}=\sigma_{1}+\sigma_{2}+\sigma_{3}\right)$;

*Tensão de cisalhamento octaédrico $\left(\tau_{o c t}=\sigma_{d} \frac{\sqrt{2}}{3}\right)$;

Fonte: Nguyen et al. (2016).

Vale ressaltar que as relações já desenvolvidas não consideram o comportamento de solos tropicais, principalmente no que diz respeito ao comportamento peculiar dos solos lateríticos (NOGAMI et al., 1981). 
De acordo com Guimarães et al. (2015), há uma boa correlação entre a metodologia MCT e a resposta resiliente dos solos tropicais, quase sempre os solos caracterizados como lateríticos apresentam elevado valor de módulo resiliente em relação aos não lateríticos. No livro de Villibor et al. (2019), são apresentados resultados de módulos de resiliência maiores para solos lateríticos do que para o solo não laterítico. Da mesma forma, Rodrigues (1997) relatou valores de MR maiores para solos lateríticos arenosos (LA') ao se comparar com os não lateríticos arenosos (NA').

O módulo de resiliência é influenciado pela granulometria. De acordo com a Manual do DNIT (2006), solos finos coesivos apresentam baixa deformidade elástica devido aos campos eletromagnéticos entre as partículas, fazendo com que sejam mais dependentes da tensão de desvio. Já os solos granulares deformam mais e são mais influenciados pela tensão confinante. Solos lateríticos estudados por Guimarães (2015) apresentaram elevado valor de módulo resiliente, podendo, inclusive, ser superior ao módulo apresentado por materiais pedregulhosos tradicionais. Delgado (2012), também chegou a mesma conclusão ao estudar um solo argiloso laterítico, o qual apresentou módulo resiliente médio igual a $393 \mathrm{Mpa}$, valor semelhante a módulo de materiais granulares, como as britas. Como evidenciado pelos autores, solos lateríticos apresentam peculiaridades resultantes no ganho na resistência e impermeabilidade, excelentes para aplicação em camadas de pavimentos.

\section{MATERIAIS E MÉTODOS}

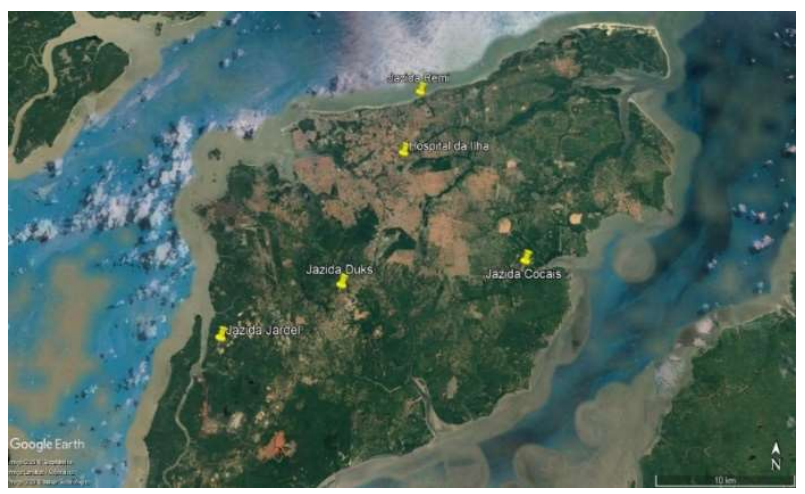

Figura 1: Planta de localização geográfica das amostras.

Nesta pesquisa, entende-se como região da llha de Maranhão, toda área compreendida pelos municípios: São Luís, Paço do Lumiar, São José de Ribamar e Raposa, no Estado do Maranhão. Na fase de pesquisa e coleta dos materiais, foram feitas visitas em quatro jazidas da região, sendo: Jazida Cocais (São José de Ribamar); Jazida Duks (bairro do Macaranã, em São Luís); Jazida Jardel (no Distrito Industrial, São Luís) e Jazida Remi (Araçagi, São Luís). Também foi estudada uma amostra retirada do subleito do estacionamento do Hospital da Ilha (Turu, São Luís). Totalizando-se em sete amostras da região, dispostas na Tabela 1 e mapeadas na Figura 1, conforme suas origens.

Tabela 2: Origem das amostras.

\begin{tabular}{ll}
\hline Origem & Identificação \\
\hline & Amostra 1 \\
Jazida Cocais & Amostra2 \\
Amostra 3
\end{tabular}


Jazida Duks

Jazida Jardel

Jazida Remi

Hospital da Ilha
Amostra 4

Amostra 5

Amostra 6

\section{Caracterização das amostras}

Para a caracterização física dos materiais foram realizados o ensaio para determinação da massa específica, (NBR 6558/2016), o ensaio de granulometria (normas NBR 7181/2016) e ensaios de limites de Atterberg (NBR 6459/2016 e NBR 7180/2016). O ensaio de ISC, normatizado pela NBR 9895, que nos permite em determinar a resistência a penetração e a expansão dos solos em condição saturada.

Foram realizadas as classificações pelos métodos tradicionais, HRB e SUCS, porém nesta pesquisa o foco foi a classificação pela metodologia MCT (Miniatura, Compactado, Tropical), a qual permite diferenciar os solos lateríticos dos não lateríticos. A metodologia MCT é baseada nas características de expansão, contração, compactação, sorção e permeabilidade e suporte. Sobretudo, para classificação MCT foram utilizados os ensaios mini-MCV (DNER-ME 256/1994) e perda de massa por imersão (DNER-ME 258/1994). $O$ ensaio de compactação foi realizado com base na norma NBR 7182 (ABNT, 2016) para amostras não trabalhadas. Optou-se por realizar os ensaios à energia proctor modificado, visando o estudo do material para emprego em camadas de base e sub-base de pavimentos.

\section{Ensaio Mecânico}

Os ensaios triaxiais de cargas repetidas para a determinação do módulo de resiliência, objeto de foco da pesquisa, foram realizados seguindo os procedimentos descrito pela na norma DNIT-ME 134/2018. Os corpos de prova foram moldados em um molde tripartido de $10 \mathrm{~cm}$ de diâmetro por $20 \mathrm{~cm}$ de altura a umidade ótima. Os pares de tensões adotados foram os mesmos descritos na norma e todos os ensaios foram realizados em duplicata.

Nesta pesquisa, através do programa STATISTICA 2.0, uma análise estatística dos resultados para os modelos descritos na Tabela 1. O processo de análise da pesquisa consiste em obter as constantes de regressão para diversos modelos descritos anteriormente, em seguida identificar aquele que melhor se encaixa aos solos da pesquisa.

\section{RESULTADOS E DISCUSSÃO}

\section{Caracterização das amostras}

O Como etapa preliminar, a caracterização do solo foi realizada no Instituto Militar de Engenharia (IME), no Laboratório de Solos. Em resumo, os valores médios encontrados no ensaio de caracterização encontram-se nas Tabelas 3. As amostras estudadas são caracterizadas como solos finos, apresentam 100\% passante na peneira de número \#10, predominantemente arenosos de coloração vermelha a laranja, variando-se a fração argila de 2 a 35\%. No que diz respeito a consistência, quatro solos apresentaram 
plasticidade e atividade baixa, e outras três amostras não apresentaram plasticidade, logo as argilas constituintes não possuem atividade.

Tabela 3: Síntese das Características das amostras.

\begin{tabular}{|c|c|c|c|c|c|c|c|}
\hline Parâmetros & Amostra 1 & Amostra 2 & Amostra 3 & Amostra 4 & Amostra 5 & Amostra 6 & Amostra 7 \\
\hline$y c\left(g / \mathrm{cm}^{3}\right)$ & 2,69 & 2,60 & 2,61 & 2,65 & 2,62 & 2,67 & 2,61 \\
\hline Limite de Liquidez (\%) & 20,20 & 20,07 & 20,46 & 16,16 & 12,54 & 24,9 & 20,28 \\
\hline Limite de Plasticidade (\%) & 14,58 & 15,43 & 13,26 & NP & NP & NP & 15,26 \\
\hline Índice de Plasticidade (\%) & 5,63 & 4,64 & 7,20 & NP & NP & NP & 5,02 \\
\hline Atividade & 0,2 & 0,1 & 3,6 & 0 & 0 & 0 & 0,2 \\
\hline Areia grossa (\%) & 2 & 1 & 15 & 2 & 1 & 6 & 2 \\
\hline Areia média (\%) & 15 & 15 & 14 & 31 & 35 & 35 & 24 \\
\hline Areia fina (\%) & 48 & 45 & 49 & 48 & 49 & 37 & 41 \\
\hline Silte (\%) & 4 & 4 & 19 & 1 & 5 & 5 & 7 \\
\hline Argila (\%) & 31 & 35 & 2 & 18 & 10 & 17 & 26 \\
\hline Classificação SUCS & SM-SC & SM-SC & SM & SM & SM & SM & $\mathrm{ML}-\mathrm{CL}$ \\
\hline Classificação AASHTO & A-4 & $\mathrm{A}-4$ & $\mathrm{~A}-4$ & $A-2-4$ & A-2-4 & A-2-4 & $A-4$ \\
\hline$c^{\prime}$ & 1,19 & 1,35 & 0,93 & 0,9 & 0,95 & 1,10 & 1,80 \\
\hline $\mathrm{e}^{\prime}$ & 1,12 & 1,06 & 1,33 & 1,80 & 1,75 & 1,85 & 1,05 \\
\hline Classificação MCT & $\mathrm{LA}^{\prime}$ & $\mathrm{LA}^{\prime}$ & NA' & NS' & NS' & NS' & LG' \\
\hline wótima (\%) & 10,1 & 10,8 & 10,3 & 9,6 & 5,2 & 7,3 & 10,4 \\
\hline yd máx. $\left(\mathrm{kN} / \mathrm{m}^{3}\right)$ & 2,06 & 2,03 & 2,05 & 1,96 & 2,10 & 2,02 & 2.04 \\
\hline ISC (\%) & 20 & 29 & 13 & 12 & 19 & 11 & 24 \\
\hline Expansão (\%) & 0,17 & 0,08 & 0,27 & 0,27 & 0,18 & 0,03 & 0,01 \\
\hline
\end{tabular}

Em todos os casos, os valores de peso aparente seco máximo apresentaram uma variabilidade aceitável, assim como os valores de umidade ótima. Os solos em estudo mostraram-se pouco expansivos, com taxa de expansão inferior a 1\%. É possível verificar características similares aos solos da região apresentados por outros autores (SILVA FILHO, 2018; SOARES, 2017; SOUSA, 2016). Segundo a classificação HRB, os solos estudados são A-4, prevendo um comportamento péssimo para subleito, e A-2-4, sendo indicados para subleito de pavimento. A classificação Unificada revelou solos do tipo SM-SC, SM e ML-CL, conforme a Tabela 3.

Quanto à classificação MCT, dois solos foram identificados como LA' (laterítico arenoso) e outro como LG' (laterítico argiloso). É previsto que esses materiais tenham alta capacidade suporte, baixa permeabilidade e baixa expansão, com previsão de ótimo comportamento para aplicação de camadas de pavimento. $\mathrm{O}$ restante das amostras apresentou comportamento não laterítico, três amostras classificadas como solos não lateríticos siltosos (NS'), não indicados devido a expansividade do silte, e uma a amostra NA' (não laterítico arenoso).

\section{Previsão do Módulo de Resiliência}

O módulo de resiliência foi obtido através de ensaio triaxial de carga repetida, o que permite avaliar a rigidez das amostras. Para emprego em camadas de pavimento, o solo arenoso fino laterítico apresenta um valor de módulo de resiliência entre 100 a 500 MPa (OSTEN,2018). O estado de tensões tem influência direta na deformação resiliente. Para solos coesivos, os campos eletromagnéticos são vencidos por deformações cisalhantes, desse modo a tensão de desvio é mais significativa. Já para solos granulares, como a resistência está ligada ao atrito entre as partículas, há uma dependência maior da tensão confinante. A literatura registra 
que solos não se enquadram em modelos lineares, em razão disso o modelo composto (PEZO et al. 1992) tem sido amplamente utilizado no Brasil.

A Tabela 4 apresenta a análise estatística dos sete modelos analisados, citados anteriormente na Tabela 1. Nesta tabela também estão os valores de Módulo de Resiliência (MR) médio. O melhor ajuste estatístico foi o observado no modelo sugerido pelo Programa Nacional de Pesquisa em Rodovias Cooperativas (NHCRP, 2004). No entanto, o modelo composto, proposto por Pezo (1992), também mostrou variabilidade adequada, sendo este o mais utilizado em projeto de pavimentos no Brasil. Os valores médios do módulo resiliente resultante da média dos valores de teste também foi apresentado nas Tabelas 4.

Tabela 4: Valores dos coeficientes de regressão e MR médio para as amostras

\begin{tabular}{|c|c|c|c|c|c|c|c|c|}
\hline $\mathrm{N}^{\circ}$ & Parâmetros & Amostra 1 & Amostra 2 & Amostra 3 & Amostra 4 & Amostra 5 & Amostra 6 & Amostra 7 \\
\hline \multirow{3}{*}{ (1) } & $k_{1}$ & 510,19 & 340,94 & 286,45 & 859,46 & 786,04 & 604,85 & 359,93 \\
\hline & $k_{2}$ & $-0,007$ & $-0,057$ & $-0,235$ & 0,2334 & 0,2117 & 0,2086 & $-0,187$ \\
\hline & $\mathrm{R}^{2}$ & 0,001 & 0,032 & 0,454 & 0,513 & 0,378 & 0,370 & 0,226 \\
\hline \multirow{3}{*}{ (2) } & $k_{1}$ & 387,19 & 340,15 & 303,66 & 521,96 & 509,84 & 365,55 & 339,34 \\
\hline & $k_{2}$ & $-0,119$ & $-0,168$ & $-0,271$ & 0,0756 & 0,0772 & 0,0424 & $-0,262$ \\
\hline & $\mathrm{R}^{2}$ & 0,220 & 0,418 & 0,903 & 0,080 & 0,075 & 0,022 & 0,664 \\
\hline \multirow{3}{*}{ (3) } & $k_{1}$ & 479,74 & 345,11 & 394,4 & 551,05 & 529,14 & 400,62 & 450,74 \\
\hline & $k_{2}$ & $-0,064$ & $-0,119$ & $-0,278$ & $-0,1785$ & 0,1665 & 0,1473 & $-0,245$ \\
\hline & $\mathrm{R}^{2}$ & 0,268 & 0,151 & 0,679 & 0,321 & 0,250 & 0,194 & 0,414 \\
\hline \multirow{4}{*}{ (4) } & $k_{1}$ & 292,134 & $206.2,4$ & 282,86 & 380.72 & 395,637 & 258,182 & 261,3 \\
\hline & $k_{2}$ & 0,5133 & 0,5063 & 0,1656 & 0,5814 & 0,5886 & 0,7466 & 0,3343 \\
\hline & $k_{3}$ & $-0,5452$ & $-0,5795$ & $-0,3962$ &,- 3892 & $-0,3703$ & $-0,5335$ & $-0,5651$ \\
\hline & $\mathrm{R}^{2}$ & 0,793 & 0,898 & 0,973 & 0,790 & 0,708 & 0,851 & 0,915 \\
\hline \multirow{4}{*}{ (5) } & $k_{1}$ & 592,385 & 415,33 & 355.752 & 848,056 & 888,448 & 722,761 & 415,62 \\
\hline & $k_{2}$ & 0,3285 & 0,3262 & 0,1065 & 0,3702 & 0,3734 & 0,4772 & 0,2169 \\
\hline & $k_{3}$ & $-0,3511$ & $-0,3994$ & $-0,3371$ & $-0,1783$ & $-0,156$ & $-0,2647$ & $-0,4472$ \\
\hline & $\mathrm{R}^{2}$ & 0,791 & 0,898 & 0,973 & 0,785 & 0,702 & 0,847 & 0,916 \\
\hline \multirow{4}{*}{ (6) } & $k_{1}$ & 193,875 & 133.357 & 209.971 & 284,121 & 299,45 & 172,844 & 170,839 \\
\hline & $k_{2}$ & 0,5133 & 0,5063 & 0,1656 & 0,5414 & 0,5886 & 0,7466 & 0,3342 \\
\hline & $k_{3}$ & $-0,5452$ & $-0,5795$ & $-0,3062$ & $-0,3892$ & $-0,3703$ & $-0,5336$ & $-0,5651$ \\
\hline & $\mathrm{R}^{2}$ & 0,793 & 0,898 & 0,973 & 0,790 & 0.708 & 0,821 & 0,915 \\
\hline \multirow{4}{*}{ (7) } & $k_{1}$ & 129,547 & 91,5438 & 131,59 & 167,229 & 171,086 & 111,693 & 117,741 \\
\hline & $k_{2}$ & 0,5292 & 0,5187 & 0,1590 & 0,6151 & 0,6362 & 0,7733 & 0,3462 \\
\hline & $k_{3}$ & $-0,6355$ & $-0,6628$ & -0.4741 & $-0,5105$ & $-0,5067$ & $-0,6397$ & $-0,6453$ \\
\hline & $\mathrm{R}^{2}$ & 0,818 & 0,912 & 0,969 & 0,827 & 0,755 & 0,884 & 0,926 \\
\hline \multicolumn{2}{|c|}{ MR médio (Mpa) } & 532 & 411 & 577 & 449 & 439 & 340 & 638 \\
\hline
\end{tabular}

A seguir, as Figuras 2 a 8 apresentam os gráficos tridimensionais obtidos para o modelo composto, por ser o mais utilizado no Brasil e modelo sugerido pela NCHRP (2014), que foi aquele que obteve melhores resultados. Embora o modelo de Witczak et al. (1988) tivesse apresentado valores semelhantes. 

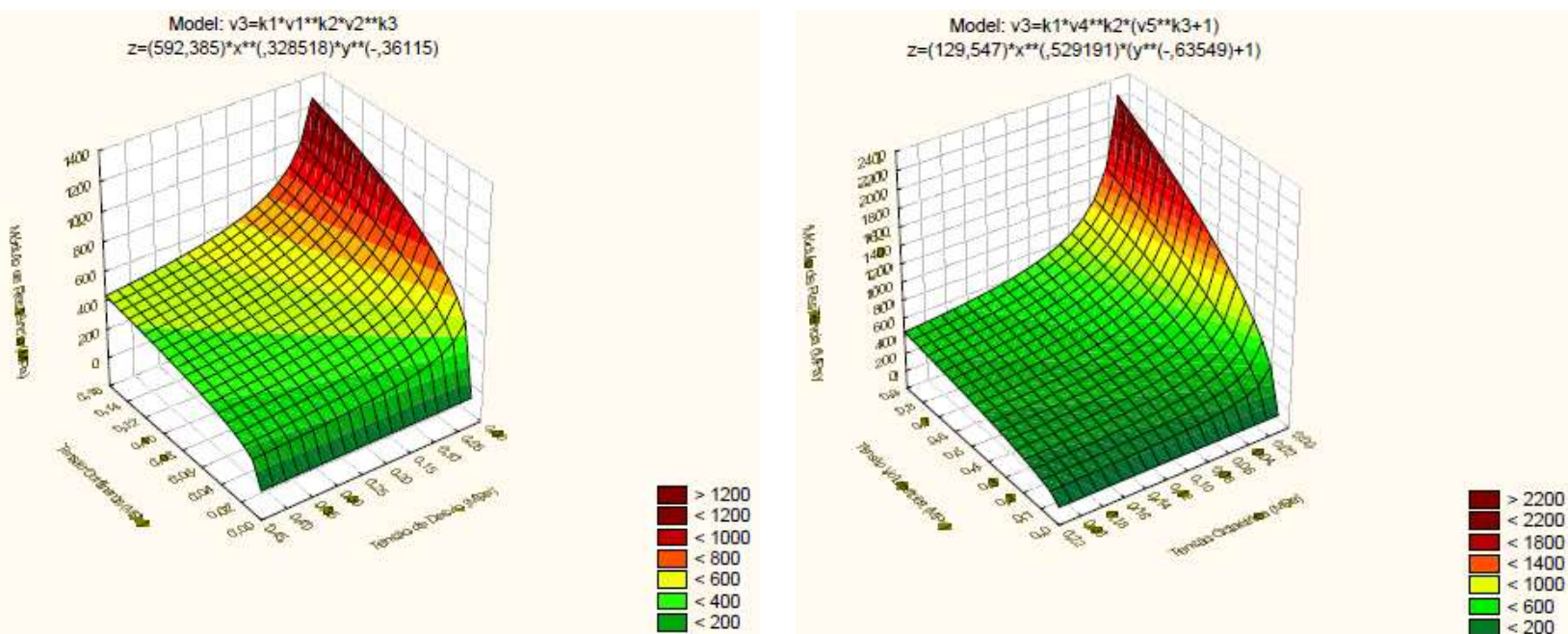

Figura 2: Gráfico tridimensional da Variação do Módulo Resiliente para a amostra 1.
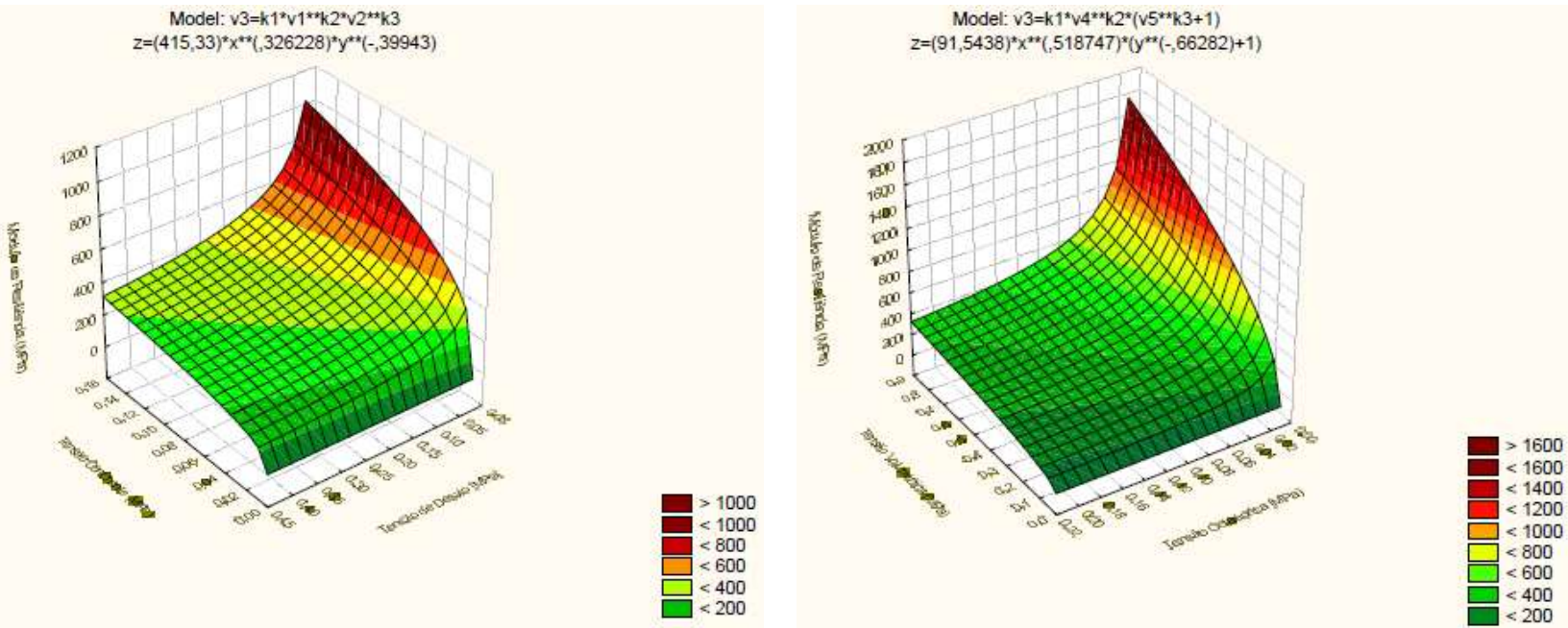

Figura 3: Gráfico tridimensional da Variação do Módulo Resiliente para a amostra 2.
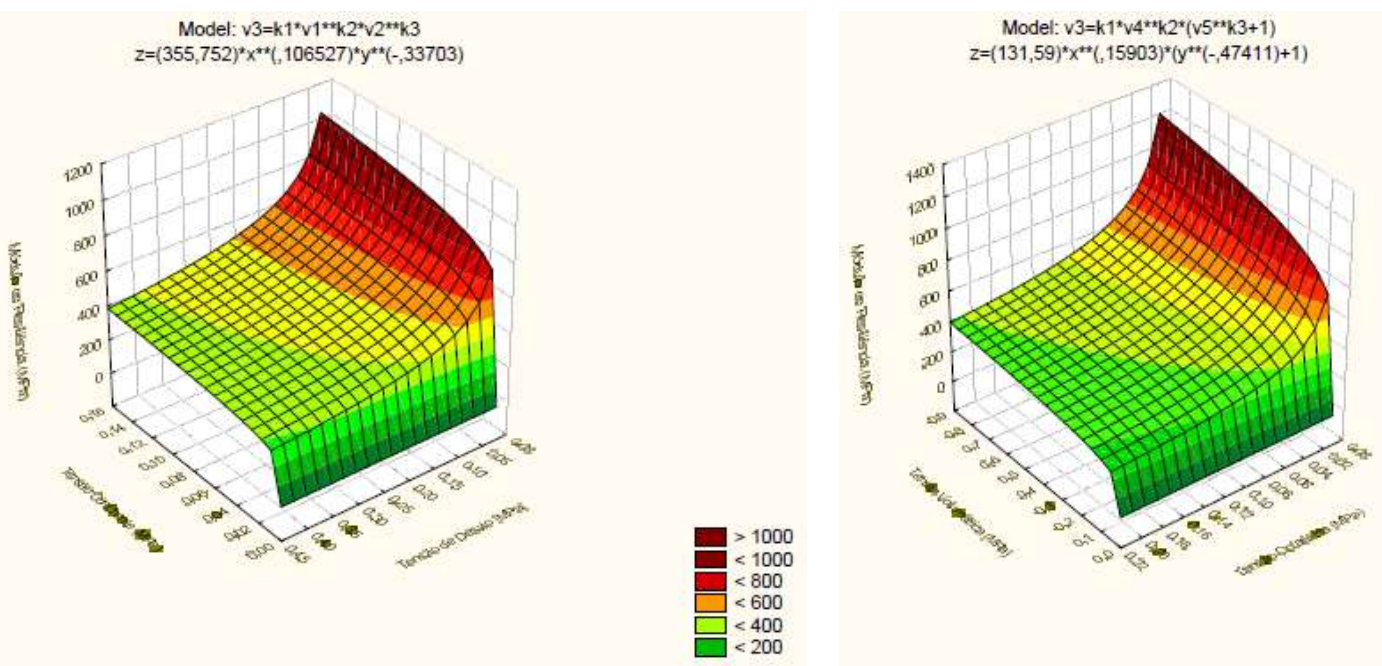

Figura 4: Gráfico tridimensional da Variação do Módulo Resiliente para a amostra 3. 

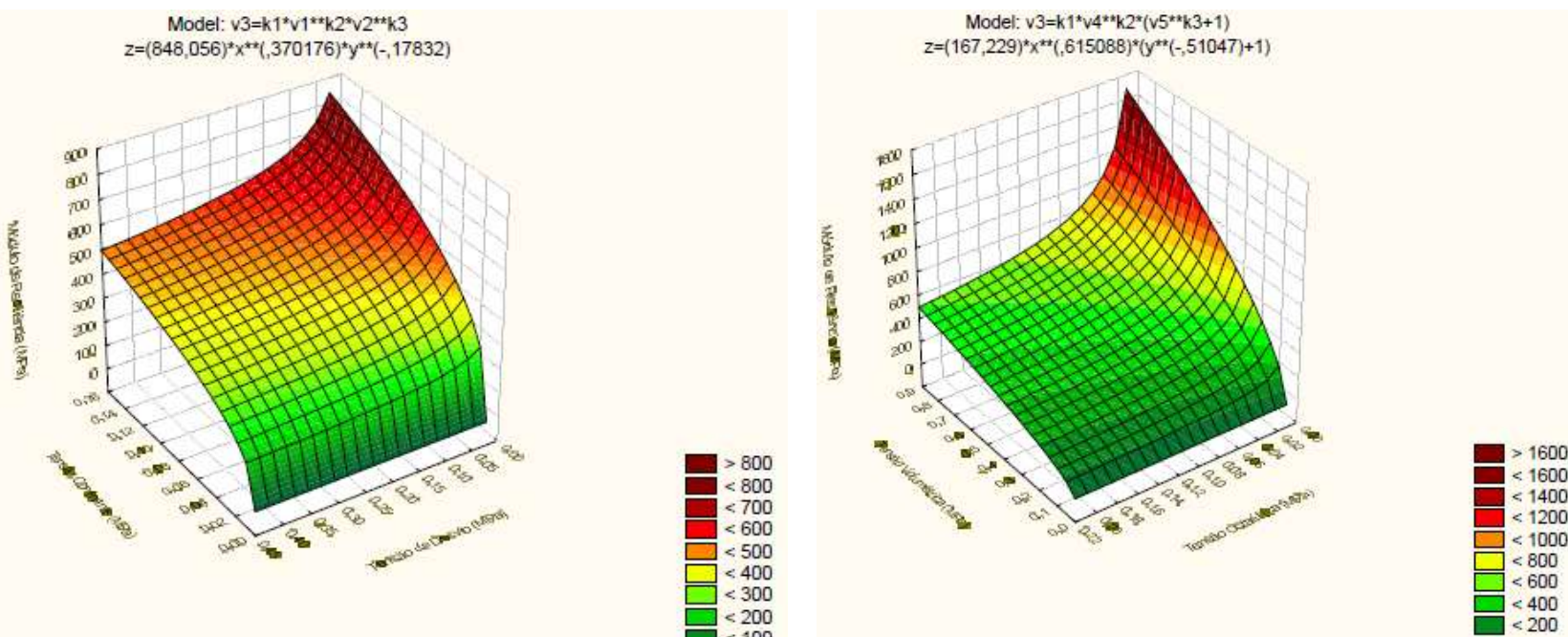

Figura 5: Gráfico tridimensional da Variação do Módulo Resiliente para a amostra 4.
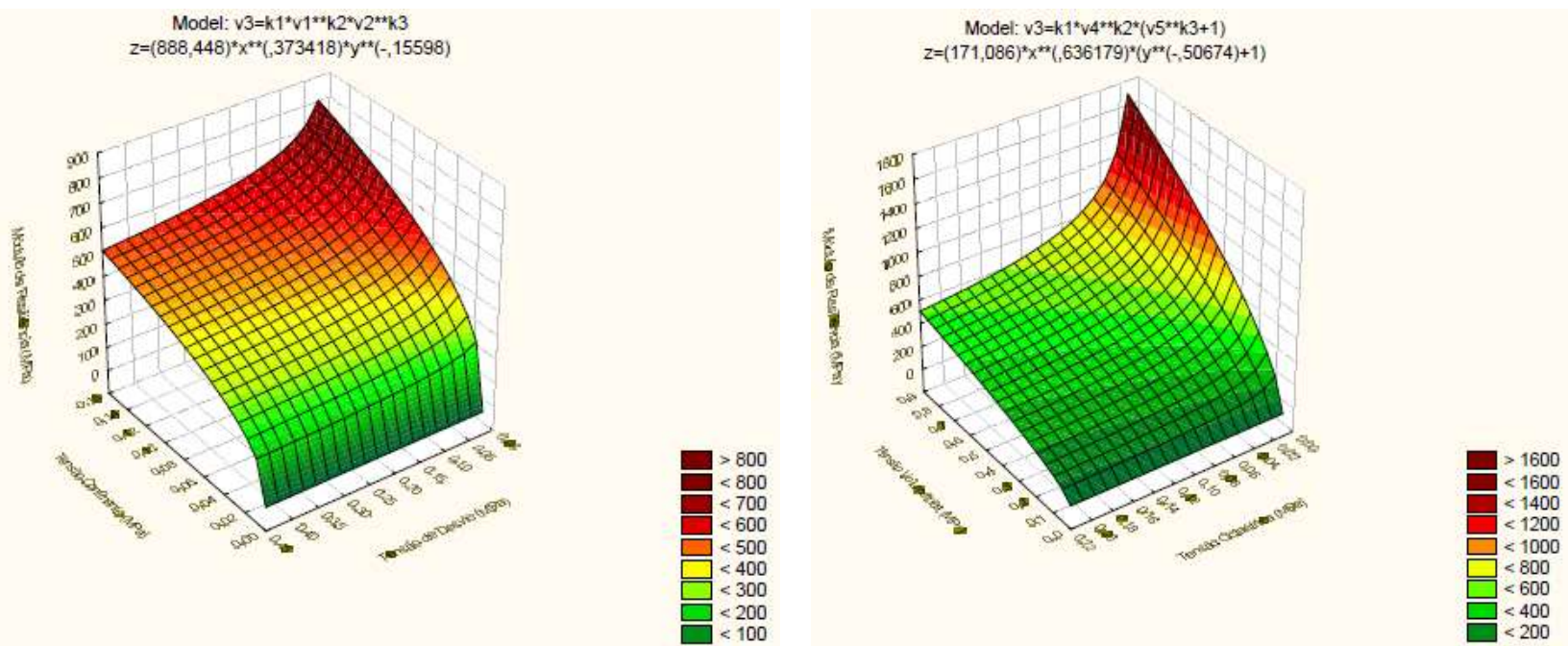

Figura 6: Gráfico tridimensional da Variação do Módulo Resiliente para a amostra 5.
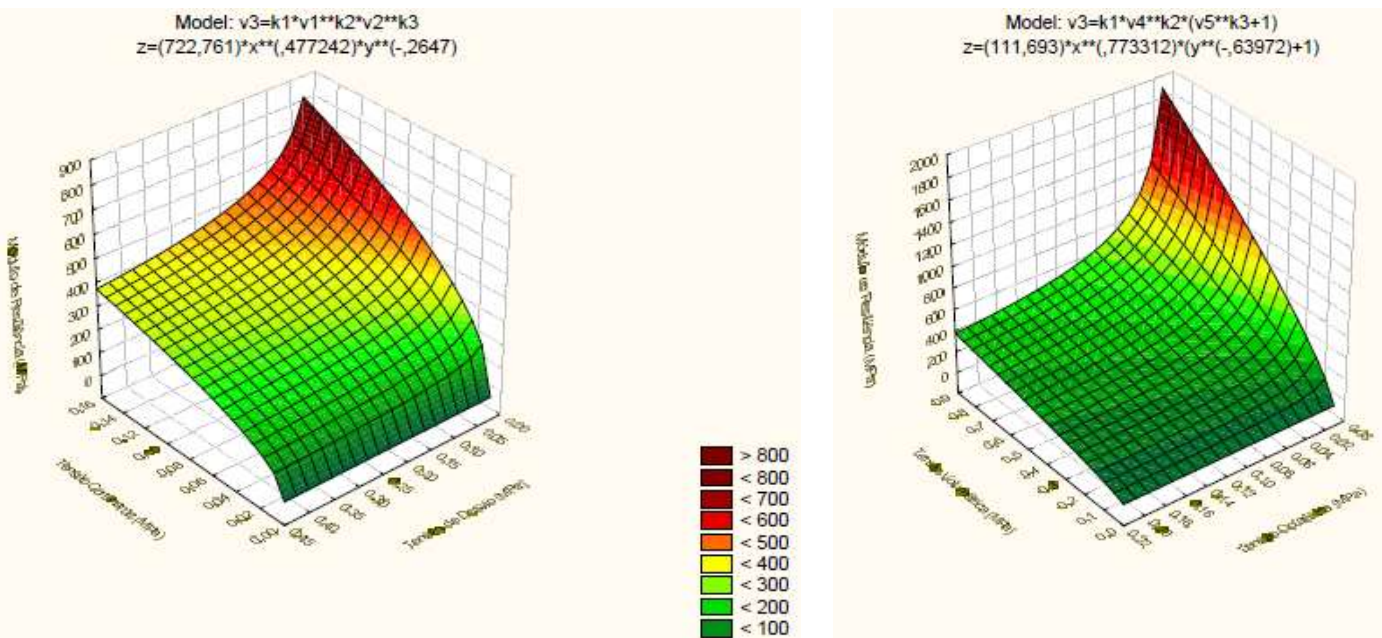

Figura 7: Gráfico tridimensional da Variação do Módulo Resiliente para a amostra 6. 

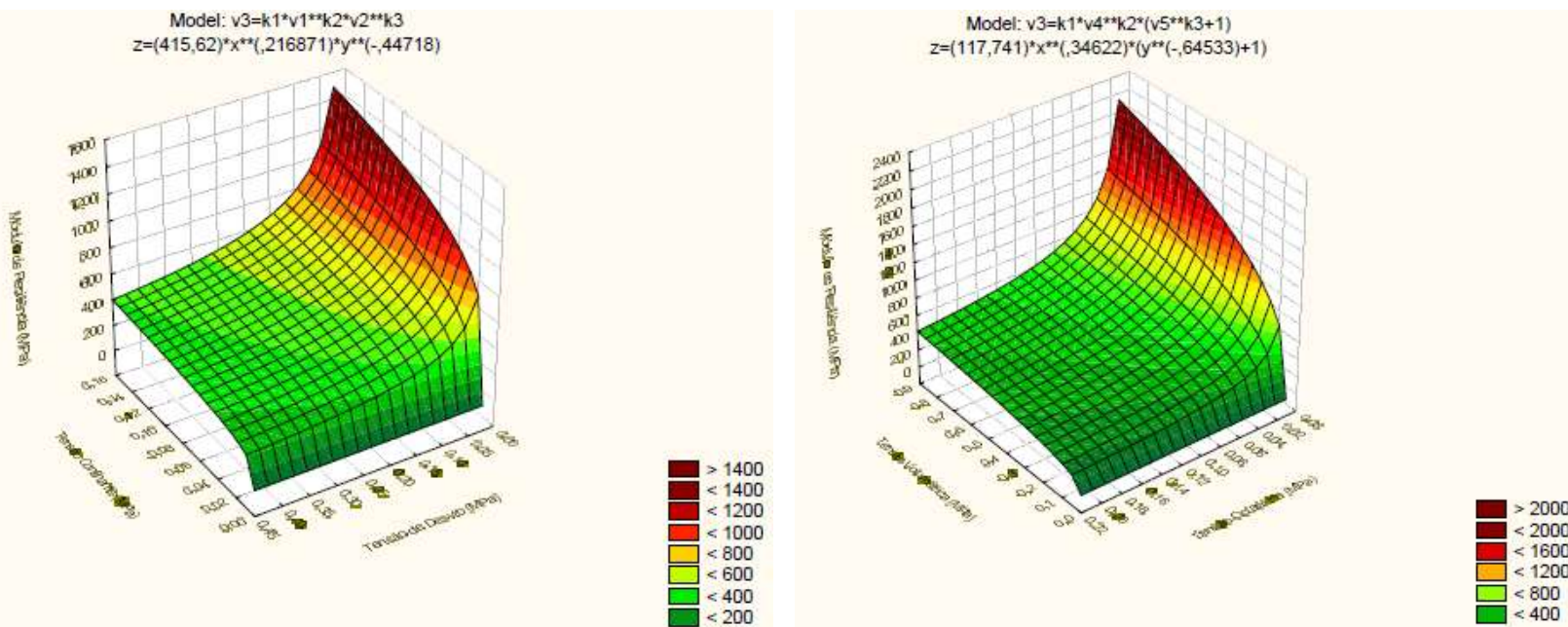

Figura 8: Gráfico tridimensional da Variação do Módulo Resiliente para a amostra 7.

\section{Discussões sobre Valores Típicos para Módulo de Resiliência}

Com base na metodologia MCT, LIMA (2020) afirma que o solo LA' é o que apresenta melhor comportamento dentre os demais solos arenosos. Depois deste vem o solo LA, e em seguida o solo NA'. O solo NA não é indicado para aplicação em base de pavimentos devido à sua alta permeabilidade e infiltrabilidade. Embora uma pesquisa da COPPE que monitorou por quase dez anos em um trecho da rodovia municipal de Campo Azul MG-202, Minas Gerais, tenha atestado o bom desempenho de base contendo um solo NA (MEDRADO, 2009). A seguir serão comentados os resultados de ensaios de módulo de resiliência obtidos para as amostras de solos estudadas conforme a classificação MCT.

De acordo com o Manual de pavimentação do DNIT (2006), é observado comportamento resiliente de médio a baixo para solos lateríticos arenosos. A amostra 1 e 2 apresentaram valor médio de $532 \mathrm{MPa}$ e $411 \mathrm{MPa}$, respectivamente. Estes valores demostram uma alta rigidez, podendo está relacionado a elevada porção de argila desses dois materiais (31 e 35\% de argila), demonstrando um bom desempenho em camadas de pavimento. Guimarães (2009), destaca valores de MR de LA' entre 220 e 300 MPa adequados para emprego em camada de base de pavimentos.

Para a amostra 3, solo laterítico não arenoso, o valor médio de MR é $577 \mathrm{MPa}$, apresentando desempenho satisfatório para camada de pavimento. Gomes et al. (2018), ao estudar solos dessa mesma classificação encontrou MRs médios entre 151 e 553 MPa. Para os solos não lateríticos siltosos os valores de MR médio são de $340 \mathrm{MPa}, 359 \mathrm{MPa}$ e $439 \mathrm{MPa}$, para as amostras 4, 5 e 6, respectivamente. 0 comportamento resiliente das amostras são adequados, porém, em geral, estes solos não são indicados para pavimentação devido a expansividade do silte. Os MRs médio encontrados por Lima (2020) ficaram na faixa de 123 a 336 MPa para esta classe, logo a amostra 6 apresentou MR superior a esta literatura.

Em desacordo o Manual de Pavimentação do DNIT (2006), que prevê módulo resiliente baixo para solo laterítico argiloso, a amostra 7, apresentou MR médio de $638 \mathrm{Mpa}$, o maior entre todos os outros solos estudados. É interessante ressaltar que o valor de MR encontrado nesse estudo, é superior aos valores de MR encontrados por Guimarães (2009), Delgado (2012), Gomes (2018) e Lima (2020). 
Todos os valores médios do módulo resiliente mostrados no item anterior, são mais altos que os intervalos e valores típicos de MR sugeridos para materiais com a mesma classificação SUCS, sugerido pelo Programa Nacional de Pesquisa Cooperativa em Rodovias Projeto 1-28aㅗ , dos Estados Unidos (Tabela 7). Esse comportamento é bastante comum em solos lateríticos, em concordância com as peculiaridades do comportamento mecânico desses solos mostradas por diversos autores (DELGADO, 2012; SOUSA, 2016; SOUSA, 2018; OSTEN 2012). O que comprova que os solos tropicais não são bem representados pelos sistemas de classificação tradicionais, como no caso a classificação SUCS.

Tabela 3: Faixas típicas de MR em relação a classificação SUCS (NCHRP, 2004).

\begin{tabular}{llll}
\hline \multirow{2}{*}{ Classificação SUCS } & \multicolumn{2}{l}{ Maixa } & MR Típico \\
\cline { 2 - 4 } & Mín. & 290 & 283 \\
\hline GW & 272 & 276 & 262 \\
\hline GP & 245 & 290 & 265 \\
\hline GF & 228 & 259 & 148 \\
\hline GC & 166 & 259 & 221 \\
\hline SW & 193 & 228 & 193 \\
\hline SP & 166 & 259 & 221 \\
\hline SF & 193 & 193 & 166 \\
\hline
\end{tabular}

Ribeiro (2016) relacionou os resultados de ensaios Geotécnico dos solos do Estado do Ceará com a classificação AASHTO para valores de estimativa de MR (Tabela 8). Embora não tenha sido na mesma região, é importante comparar os resultados, pois se trata de uma pesquisa realizada com solos brasileiros de um estado vizinho. Para solos da família A-4, os valores de MR médio encontrados foram entre 411 e 638 MPa, superiores aos valores típicos sugeridos para esta classificação. Entretanto, vale ressaltar que todos esses solos apresentaram natureza laterítica, segundo a classificação MCT, o que pode justificar o bom desempenho mecânico desses materiais. Aqueles classificados como A-2-6, tiveram seus valores na faixa 340 a 449 MPa, próximo aos da faixa sugerida. Já para a amostra 8, classificada como da família A-2-4, o valor de MR encontrado de $393 \mathrm{MPa}$, está dentro da faixa sugerida pelo autor.

Tabela 8: Valores Típicos do Módulo de Resiliência para solos do Ceará (Ribeiro, 2016).

\begin{tabular}{llll}
\hline \multirow{2}{*}{ Classificação da AASTHO } & Faixa & \multicolumn{2}{c}{ Máx. } \\
\cline { 2 - 4 } & Mín. & 290 & 283 \\
GW & 272 & 276 & 262 \\
GP & 245 & 290 & 265 \\
GF & 228 & 259 & 221 \\
GC & 166 & 259 & 228 \\
SW & 193 & 228 & 193 \\
\hline SP & 166 & 259 & 221 \\
\hline SF & 193 & 193 & \\
\hline
\end{tabular}

\section{CONCLUSÕES}

Com o objetivo de contribuir para a previsão do comportamento de solos finos da Ilha do Maranhão, geraram-se parâmetros para diversos modelos a fim de identificar o mais adequado aos solos da região. Para as sete amostras estudadas: três solos NS', dois solos LA', um solo LG' e um solo NA'. Todas as amostras apresentam valores de módulo de resiliência média adequados para aplicação em camadas de pavimentação, seguindo a seguinte ordem: $L G^{\prime}>N A^{\prime}>L^{\prime}$ > NS'. 
Os resultados das correlações estatísticas mostraram que o modelo sugerido pela NCHRP (2004) apresentou os melhores ajustes matemáticos, sendo os seus parâmetros mais confiáveis. Além desse, o modelo composto, que é geralmente utilizado por projetistas no Brasil, também mostrou boa adequabilidade para a maioria dos solos.

A peculiaridade dos solos tropicais e a falha na classificação por parte dos sistemas de classificações internacionais foram evidentes ao se comparar os valores sugeridos pela NCHRP (2004). Todos os materiais apresentaram valores de MR superiores ao descrito em norma no que se refere aos solos empregados em subleitos rodoviários. Todavia os módulos de resiliência mostraram-se mais compatíveis ao se comparar aos estudos realizados por Ribeiro (2014). Com exceção os solos da família A-4, o que já era esperado um desempenho superior devido suas características lateríticas.

Espera-se que este estudo venha auxiliar na previsão do comportamento mecânico dos solos do Maranhão para emprego em camadas de pavimento. Sua importância se dá também a aprovação do método de dimensionamento empírico-mecanístico brasileiro, que emprega o ensaio triaxial para determinação dos parâmetros, este em fase de discussão e construção de banco de dados. Vale ressaltar o ensaio de módulo de resiliência ainda tem algumas barreiras para se consagrar no meio comercial, como por exemplo a ausência de uma calibragem, custo elevado e a escassez do equipamento no território brasileiro. Contudo, entender o comportamento dos solos e qual o modelo mais adequado para solos da região aumentará a acurácia dos projetos, poupando-se gastos com intervenções prematuras, oriundas de erros de projeto relacionados com a má aplicação do ensaio de módulo de resiliência.

\section{REFERÊNCIAS}

ABNT. Associação Brasileira de Normas Técnicas. NBR 6558: Grãos de solos que passam na peneira de $4,8 \mathrm{~mm}$ : Determinação da massa específica. Brasília: ABNT, 2016.

ABNT. Associação Brasileira de Normas Técnicas. NBR 7181: Solo: Análise granulométrica. Brasília: ABNT, 2016.

ABNT. Associação Brasileira de Normas Técnicas. NBR 7180: Solo: Determinação do Limite de Plasticidade. Brasília: ABNT, 2016.

ABNT. Associação Brasileira de Normas Técnicas. NBR 6459: Solo: Determinação do Limite de Liquidez. Brasília: ABNT, 2016.

ABNT. Associação Brasileira de Normas Técnicas. NBR 7182: Solo: Ensaio de compactação. Brasília: ABNT, 2016.

ABNT. Associação Brasileira de Normas Técnicas. NBR 9895: Solo: Índice de Suporte Califórnia. Brasília: ABNT, 2016.

AUSTROADS. A guide to the structural design of road pavements. Camberra: Austroads Inc., 2012.

BASTOS, J. B. S.. Influência da variação da umidade no comportamento de pavimentos da região metropolitana de Fortaleza. Dissertação (Mestrado) - Universidade Federal do Ceará, Fortaleza, 2013.
CARDOSO, S. H.. Estudo das deformações resilientes de solos lateríticos da região de Brasília. In: REUNIÃO ANUAL DE PAVIMENTAÇÃO, 23. Anais. Florianópolis: ABPV, 1988. p.203-219.

DELGADO, B. G.. Análise da deformabilidade de um solo tropical do oeste do Maranhão como camada de sublastro na estrada de ferro Carajás. Dissertação (Mestrado) Universidade Federal de Ouro Preto, Ouro Preto, 2012.

DNIT. Departamento Nacional de Infraestrutura de Transportes. 134/2018-ME: Pavimentação: Solos: Determinação do módulo de resiliência: Método de ensaio. Brasília: DNIT, 2018.

DNIT. Departamento Nacional de Infraestrutura de Transportes. Manual de Pavimentação Rodoviária. Publicação IPR 719. Diretório de Planejamento e Pesquisa, Instituto de Pesquisas Rodoviárias. Rio de Janeiro: DNIT, 2006.

DNER. Departamento Nacional de Estradas de Rodagem. DNER-ME 256/94. Solos compactados com equipamento miniatura: determinação da perda de massa por imersão. 1984.

DNER. Departamento Nacional de Estradas de Rodagem. DNER-ME 258/94. Solos compactados com equipamento miniatura - Mini-MCV. 1984. 
FERNANDES, P. G. P. S.; VALOURA, L. R.; ESPIMNDOLA, A. C.; CIRIMACO, T. G. M.. Estudo comparativo dos métodos empírico do DNER e mecanístico-empírico pelo SISPAV aplicado a rodovia BR-316. In: CONGRESSO NACIONAL DE PESQUISA EM TRANSPORTE, 31. Anais. Recife: ANPET, 2017. p.1217-1226.

FERNANDES, W. D.. Análise comparativa entre os métodos de dimensionamento de pavimentos flexíveis do Brasil e o método da AASHTO. Dissertação (Mestrado) - Universidade Federal de Santa Maria, Santa Maria, 2016.

FRANCO, F. A. C. P.. Método de dimensionamento mecanístico-empírico de pavimentos asfálticos - SISPAV. Dissertação (Mestrado em Engenharia Civil) - Universidade Federal do Rio de Janeiro, Rio de Janeiro, 2007.

GOMES, M. S.; GUIMARÃES, A. C. R.; MARQUES, M. E. S. Estudo da influência do tipo de finos no comportamento resiliente de solos tropicais para uso em pavimentos. Revista Ibero-Americana de Ciências Ambientais. v.9, n.5, p.78-87, 2018.

GUIMARÃES, A. C. R.. Um Método Mecanístico Empírico para Previsão da Deformação Permanente em Solos Tropicais Constituintes de Pavimentos. Tese (Doutorado em Engenharia Civil) - Universidade Federal do Rio de Janeiro, Rio de Janeiro, 2009.

HICKS, R. G.; MONISMITH, C. L.. Factors influencing the resilient response of granular materials. Highway Research Record, n.345, p.15-31, 1971.

LI, D.; SELIG, E.. Resilient modulus for fine-grained subgrade soils. Journal of Geotechnical Engineering, v.120, n.6, p.939957, 1994.

LIMA, C. D. A.. Avaliação da deformação permanente de materiais de pavimentação a partir de ensaios triaxiais de cargas repetidas. Tese (Doutorado em Engenharia Civil) Universidade Federal do Rio de Janeiro, Rio de Janeiro, 2020.

MEDINA, J.; MOTTA, L. M. G.. Mecânica dos Pavimentos. 3 ed. Rio de Janeiro: Interciência, 2015.

MEDINA, J.; MOTTA, L. M. G.; SANTOS, J. D. G.. Deformability characteristics of Brazilian laterites. Geotechnical and Geological Engineering, v.24, p.949-971, 2006.

MEDINA, J.; PREUSSLER, E. S.. Características resilientes de solos em estudos de pavimentos. Rio de Janeiro: Solos e Rochas, 1980.

MEDRADO, W. A.. Caracterização geotécnica de solo da região norte de Minas Gerais para aplicação em obras rodoviárias. Dissertação (Mestrado) - Universidade Federal de Ouro Preto, Ouro Preto, 2009.

NHCRP. National Highway Cooperative Research Program. Project 1-28A. Laboratory determination of resilient modulus for flexible pavement design. National cooperative highway research program research results digest No. 285 . 2004.

NGUYEN, B. T.; MOHAJERANI, A.. Resilient modulus of finegrained soil and a simple testing and calculation method for determining an average resilient modulus value for pavement design. Transportation Geotechnics, v.7, p.59-70, 2016.

VILLIBOR, D. F.; ALVES, J. S.. Pavimentação de baixo custo em regiões tropicais. São Paulo: ABDER, 2019.

NOGAMI, J. S.; VILLIBOR, D. F.. Uma nova classificação de solos para finalidades rodoviárias. In: BRAZILIAN SIMPOSIUM OF TROPICAL SOILS IN ENGINEERING. Anais. Rio de Janeiro, 1981. p.30-41.

NOGAMI, J. S.; VILLIBOR, D. F.. Estudos geotécnicos e de drenagem aplicados à pavimentação. In: REUNIÃO ANUAL DE PAVIMENTAÇÃO, 18. Anais. Porto Alegre: Associação Brasileira de Pavimentação, 1983. p.465-484.

OSTEN, F. B.. Avaliação de solos tropicais para sublastro da estrada de Ferro Carajás. Dissertação (Mestrado) - Instituto Militar de Engenharia, Rio de Janeiro, Brasil, 2012.

PEZO, R. F.; CLAROS, G.; HUDSON, W. R.; STOKOE II, K. H.. Development of a reliable resiliente modulus test for subgrade and non-granular subbase materials for use in routine pavement design. Research Report 1177-4F. Austin: Center for Transportation Research, 1992.

PREUSSLER, E. S.. Ensaios triaxiais dinâmicos e um solo arenoso. Dissertação (Mestrado) - Universidade Federal do Rio de Janeiro, Rio de Janeiro, 1978.

RIBEIRO, A. J. A.. Um modelo de previsão do módulo de resiliência dos solos no estado do Ceará para fins de pavimentação. Tese (Doutorado) - Universidade Federal do Ceará, Fortaleza, 2016.

RODRIGUES, M. R.. Influência da sucção no módulo de resiliência dos solos típicos de subleito de pavimentos do Rio do Grande do sul. Dissertação (Mestrado) Universidade Federal do Rio Grande do Sul, Porto Alegre, 1997.

SANTOS, T. A.. Avaliação da resistência e da deformabilidade de quatro solos empregados em subleitos rodoviários no estado do Rio Grande do Sul. Dissertação (Mestrado) - Universidade Federal de Santa Maria, Santa Maria, 2016

SANTOS, T. A.; SPETCHT, L. P.; PINHEIRO, R. J. B.; CERATTI, J. A. P.; BRITO, L. A. T.. Avaliação da resistência e da deformação resiliente de quatro solos de subleitos rodoviários no estado do Rio Grande do Sul. Revista Transportes, v.27, n.1, 2019.

SILVA FILHO, J. C.. Contribuição para o desenvolvimento de um método de dimensionamento mecanístico-empírico de pavimentos ferroviários com foco nos solos tropicais. Tese (Doutorado) - Instituto Militar de Engenharia, Rio de Janeiro, 2018.

SOUSA, M. A. S.. Análise geotécnica de solos tropicais de ocorrência ao longo da Estrada de Ferro Carajás para uso como camadas de pavimento ferroviário. Dissertação (Mestrado) - Instituto Militar de Engenharia, Rio de Janeiro, 2016. 
SOUSA, M. S.. Estudo de solos tropicais de granulometria transicional para emprego em pavimento ferroviário. Dissertação (Mestrado) - Instituto Militar de Engenharia, Rio de Janeiro, 2018.

SPADA, J. L. G.. Uma abordagem de mecânica dos pavimentos aplicada ao entendimento do mecanismo de comportamento tensão-deformação da via férrea. Tese (Doutorado em Engenharia Civil) - Universidade Federal do Rio de Janeiro, Rio de Janeiro, 2003.

SVENSON, M.. Ensaios triaxiais dinâmicos de solos argilosos. Dissertação (Mestrado) - Universidade Federal do Rio de Janeiro, Rio de Janeiro, 1980.
TUTUMLUER, E.; SEYHAN, U.. Neural network modeling of ansisotropic aggregate behavior from repeated load triaxial tests. Tansportation Research Record, n.1615, p.85-93, 1998.

UZAN, J.. Characterization of granular material. Transportation Research Record, n.1022, p.52-59, 1985.

VIANA, H. M. F.. Estudo do comportamento resiliente dos solos tropicais grossos do interior do Estado de São Paulo. Tese (Doutorado) - Escola de Engenharia de São Carlos, São Paulo, 2007.

YUAN, D.; NAZARIAN, S.. Variation in moduli of base and subgrade with moisture. Washington: Transportation Research Board 82nd Annual Meeting, 2013.

A CBPC - Companhia Brasileira de Produção Científica (CNPJ: 11.221.422/0001-03) detém os direitos materiais desta publicação. Os direitos referem-se à publicação do trabalho em qualquer parte do mundo, incluindo os direitos às renovações, expansões e disseminações da contribuição, bem como outros direitos subsidiários. Todos os trabalhos publicados eletronicamente poderão posteriormente ser publicados em coletâneas impressas sob coordenação da Sustenere Publishing, da Companhia Brasileira de Produção Científica e seus parceiros autorizados. Os (as) autores (as) preservam os direitos autorais, mas não têm permissão para a publicação da contribuição em outro meio, impresso ou digital, em português ou em tradução. 